\title{
O Violoncello piccolo a 4 e 5 cordas: Uma análise através das fontes iconográficas históricas
}

\section{The 4 and 5 strings Violoncello Piccolo: An Analysis through Historical Iconographic Sources}

\author{
(iD) Edoardo Sbaffi \\ Universidade do Estado do Amazonas, Manaus, Amazonas, Brasil \\ edoardosbaffi@gmail.com
}

Resumo: Esta pesquisa dedica-se a investigar a presença, o uso e as técnicas executivas de algumas variantes do violoncelo barroco: os violoncelos de pequenas dimensões (violoncello piccolo) a 4 cordas e os violoncelos de 5 cordas ao longo dos séculos XVI, XVII e XVIII. É difícil demonstrar o uso desses peculiares modelos de baixos de corda friccionada por meio de documentos escritos (tratados históricos e partituras) por causa da terminologia aproximativa e abrangente da época. Por outro lado, em relação aos instrumentos originais, conservados em museus e coleções particulares, há frequentes dúvidas a respeito de sua autenticidade. Nesse cenário, a Iconografia Musical torna-se uma preciosa fonte de informação. Após uma breve descrição das principais fontes primárias, será apresentada e interpretada uma coletânea de frescos, pinturas a óleo e gravuras representando esses modelos de baixo, seguindo uma ordem cronológica.

Palavras-chaves: Iconografia musical. Violoncello piccolo. Violoncelo a 5 cordas.

Abstract: This research investigates the presence, the use and the techniques of some variants of the baroque cello: small cellos (violoncello piccolo) with 4 strings and 5 string cellos throughout 
the sixteenth, seventeenth and eighteenth centuries. The use of these peculiar models of bowed basses is difficult to demonstrate through written documents (historical treatises and scores) because of the confusing and comprehensive terminology of the time. In the other and the original instruments preserved in museums and private collections, often presents doubts of authenticity. In this scenario Musical Iconography ends up being a precious source of information. After a brief description of the main primary sources, a collection of frescoes, oil paintings and engravings representing these models of bass violins will be presented and interpreted following a chronological order.

Keywords: Musical Iconography. Violoncello Piccolo. 5 String Cello. 
O violoncello Piccolo a 4 e 5 cordas: uma análise através...

Edoardo Sbaffi

Esta pesquisa dedica-se a investigar o uso de violoncelos de pequenas dimensões (violoncello piccolo) a 4 e 5 cordas e outros modelos de violoncelo na época barroca. O início do século XVII viu a família das violas da Braccio ${ }^{1}$ dominar progressivamente 0 cenário musical europeu em geral (com exceção da França e de parte da Inglaterra) e italiano em particular, domínio que se manteve durante toda a época barroca. Nas palavras do pioneiro da organologia, Curt Sachs:

Houve uma razão cromática também. O gosto da Renascença, tanto na pintura como na música, preferiu a alternância de cores contrastantes. O século XVII, novamente tanto na pintura como na música, preferiu uma cor dominante, de fato o monocromático. Na música, esta cor dominante foi o timbre dos instrumentos de corda friccionada². (SACHS, 1940, p. 352).

O termo violoncello foi utilizado pela primeira vez em 1665 numa publicação de partituras de Giulio Cesare Arresti (Sonate a 2 e a Tre con la parte del violoncello a beneplacito Op. IM), em Veneza, mas demorou mais de cinquenta anos para ser aceito universalmente entre os músicos europeus. O instrumento, porém, existiu bem antes do seu nome: utilizando um corpo muito parecido, se não idêntico; tinha simplesmente uma afinação diferente. Se o termo violone é genérico e inclui todos os instrumentos de corda friccionada de registro grave ${ }^{3}$, basso di viola da braccio, bassetto, violoncino ou violono, para citar somente alguns dos termos em italiano utilizados em partituras da época, são, de fato, sinônimos de violoncelo - pelo menos até o fim do século XVII. Neste século houve muita pesquisa e experimentação por parte dos liuthiers, 0 que culminou na famosa escola de Cremona e no mais icônico dos seus membros: Antonio Stradivari, responsável pelo desenvolvi-

\footnotetext{
1 A família do violino foi designada pelos tratadistas italianos do século XVI de viole da Braccio para distingui-la da outra família de instrumentos a corda friccionada: as violas da Gamba.

2 There was a coloristic reason as well. The taste of the Renaissance, in painting as in music, had favored the alternation of contrasting colors. The seventeenth century, again in painting as in music, preferred dominating color, indeed monochromes. In music, this dominating color was the timbre of the bowed instruments. (Todas as traduções são do autor).

3 Stephen Bonta ajuda-nos a entender a evolução do violone, termo ambíguo que identificou genericamente os instrumentos de registro grave de ambas as famílias das violas. A partir de um determinado momento o termo violone (sem ulteriores adjetivos) começou a incluir os instrumentos de 12 e 16 pés enquanto continuava a identificar os de 8 pés.
} 
O violoncello Piccolo a 4 e 5 cordas: uma análise através...

mento da "forma B" que atualmente é utilizada como referência na construção do violoncelo.

O resultado desta pesquisa demonstra que o violoncelo do século XVII incluía modelos de 4 e 5 cordas numa variedade de caixas harmônicas diferentes por forma e dimensão; essa variedade continuou durante uma boa parte do século XVIII. Temos, portanto, que encontrar uma terminologia apropriada: o que é um violoncelo e quais são os limites desta definição? A opinião de um grupo de musicólogos e estudiosos, dentre eles M. Vansheeuwijck, G. Barnett, B. Wissik e D. Badiarov, é que o termo violoncelo não se deve limitar a definir um instrumento de quatro cordas tocado em posição da Gamba (na técnica da Gamba o instrumento é sustentado verticalmente entre os joelhos e os tornozelos sem uso do espigão), mas que inclui uma quantidade de variantes (com 4, 5 e até 6 cordas, frequentemente definidos como "instrumentos híbridos" ou simples "experimentos") e eram tocados com diferentes técnicas (em posição mais ou menos horizontal: da Spalla e da Collo4, ou em posição vertical, tanto da Gamba como apoiados em pequenos bancos ou espigões sendo muitas vezes simplesmente apoiados no chão). Adotando essa definição ampla do termo violoncelo, o violoncelo a 5 cordas e o violoncelo piccolo a 4 e 5 cordas passam a representar categorias ou tipos de violoncelo.

Analisando as fontes primárias observa-se que as notícias sobre o uso do violoncelo a 5 cordas são escassas, sendo as mais precisas ligadas a J.S. Bach que prescreve, para a Suíte n. 6 (BWV 1012), um instrumento a cinco cordas. Curt Sachs comenta:

\footnotetext{
O violoncello a cinque corde, em vez, que Bach prescreve a volta de 1720 para a sexta das suas suítes para violoncelo solo, não era necessariamente um violoncelo piccolo. O fato que teria sido difícil manter uma corda afinada em $\mathrm{Mi}^{3}$ sem rompe-la num instrumento grande, porém, sugere o uso de um violoncelo
}

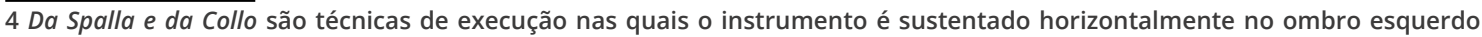
(Spalla significa ombro em italiano) ou no peito com o auxílio de um cinto que passa atrás das costas, como nas modernas guitarras elétricas.
} 
O violoncello Piccolo a 4 e 5 cordas: uma análise através...

Edoardo Sbaffi

pequeno com cinco cordas em vez do violoncelo normal ${ }^{5}$.

(SACHS, 1940, p. 392).

Na verdade, a maior parte dos compositores barrocos e pré-clássicos preocupava-se pouco com o instrumento que iria ser utilizado para a execução da obra. Limitavam-se, frequentemente, a pôr nas partituras indicações genéricas como "basso" e "violone" ou, mais tarde, "violoncello", incluindo assim todos os instrumentos que tivessem um registro equivalente. Os editores, também preocupados com um mercado de partituras muito caras e, portanto, elitista, evitavam indicações excessivamente específicas para não desincentivar eventuais compradores. A propósito, Badiarov afirma:

\begin{abstract}
Os compositores barrocos, incluindo Bach, não se preocupavam de como os instrumentos eram segurados ou do tamanho deles. Às propriedades acústicas e simbólicas dos instrumentos e à extensão do registro era dada a prioridade absoluta a detrimento da forma como eram manuseados pelos executores, aspecto que era deixado à preferência pessoal dos músicos ${ }^{6}$. (BADIAROV, 2007, p. 127).
\end{abstract}

É outra vez J.S. Bach quem utiliza primeiro, na história, o termo violoncello piccolo (em italiano) em 9 das suas cantatas compostas nos anos 20 do século XVIII. O instrumento é utilizado no papel "concertante" em árias a solo. Ainda analisando o uso dos termos, um provável sinônimo de violoncello piccolo é o violoncello da spalla, denominação utilizada por Bartolomeo Bismantova, em 1677, que no seu Compendio Musicale o define como "alla moderna", ou seja, descreve-o como se fosse uma novidade. A relação entre os dois instrumentos torna-se evidente com Johann Mattheson, um

\footnotetext{
5 The violoncello a cinque corde, on the contrary, that Bach prescribed at about 1720 in the sixth of his suites for cello solo, was not necessarily a violoncello piccolo. But the fact that it would be hard to keep an $\mathrm{e}^{1}$ string from breaking on a large instrument suggests a small cello with five strings rather than the usual cello.

6 Baroque composers, including Bach, did not concern themselves with how instruments where held, or what size they were. The acoustic and symbolic properties of instruments and their tessitura were given absolutely priority over the way they were handled by performers, which was left to the personal preference of the players.
} 
O violoncello Piccolo a 4 e 5 cordas: uma análise através...

Edoardo Sbaffi

contemporâneo de Bach, que no seu Das Neu-eröffnete Orchestre descreve o violoncelo assim:

\begin{abstract}
O violoncelo é um instrumento baixo Italiano, não diferente da Violadigamba [sic], que é tocado quase como um violino, em particular é sustentado e tocado com a mão esquerda e é, em parte por causa do seu peso, agarrado a um botão da casaca e com a mão direita usa-se o arco. É afinado como uma Viola7. (MATTHESON, 1713, p. 285-286).
\end{abstract}

Dez anos antes, Sébastien de Brossard descrevia um instrumento parecido no seu Dictionaire de 1703: "VIOLONCELO: é precisamente a nossa viola [Quinte de Violon], ou um pequeno baixo de violino a cinco ou seis cordas"(BROSSARD, 1703, p. 66).

Leopold Mozart, no seu célebre Versuch einer grundlichen Violinschule de 1756, escreve uma frase tanto lapidária quanto intrigante logo no seu primeiro capítulo; elencando os vários instrumentos de corda friccionada no seu tempo afirma: “O sétimo tipo é chamado Bassell ou Bassete, que os italianos chamam Violoncello. Antigamente tinha cinco cordas, hoje somente quatro ${ }^{8}$ (MOZART, 1756, p. 3).

Já J. B. La Borde, no seu Essai sur la musique ancienne et moderne, obra enciclopédica em dois tomos, de 1780, comprova a existência e o uso do violoncelo a cinco cordas na França, pelo menos até o início do século XVIII. Descrevendo instrumentos e gêneros musicais, La Borde conta algumas histórias e anedotas acerca dos intérpretes mais famosos. Na entrada violoncelle (no Tomo Primeiro), La Borde aborda o suposto primeiro grande violoncelista francês: Padre Tardieu de Tarascon (ativo na Provença).

\footnotetext{
7 Violoncello ist ein Italiänisches, einer Violadigamba nicht ungleiches Bass-Instrument, wird fast tractiret wie eine Violine, neml. es wird mit der lincken Hand theils gehalten, und die Griffe formiret, theils aber wird es wegen der Schwere an des Rockes Knopff gehänget und durch die rechte Hand mit ein Bogen gestrichen. Wird gestimmet wie eine Viola.

Die siebente Art heißt das Bassell oder Bassette, welches man, nach dem italiänischen Violoncello, das Violoncell nennet. Vor Zeiten hatte es 5. Seyten; itzt geigt man es nur mit vieren.

8 Die siebente Art heißt das Bassell oder Bassette, welches man, nach dem italiänischen Violoncello, das Violoncell nennet. Vor Zeiten hatte es 5. Seyten; itzt geigt man es nur mit vieren.
} 
O violoncello Piccolo a 4 e 5 cordas: uma análise através...

Edoardo Sbaffi

\section{Violoncelo.}

Instrumento que sucedeu à Viola [da Gamba] no acompanhamento dos concertos. É feito como um violino exceto que é muito maior e segura-se entre as pernas.

O Padre Tardieu, de Tarascon, irmão de um célebre Maestro de Cappella da Provença, imaginemos, no início deste século; o montou com cinco cordas, assim afinadas:

Dó (Bordão), sol (segunda), ré (terceira), lá (quarta), ré (quinta);

Ele fez uma fantástica fortuna com este instrumento, que toca bem. Quinze ou vinte anos mais tarde, reduziu o Violoncelo para quatro cordas, tirando a quinta ré9. (LA BORDE, 1780: Tome I, p. 309).

A gravura que acompanha essa entrada do Tomo Primeiro mostra um violoncelo de 4 cordas; o instrumento, porém, parece ser bem menor do que um violoncelo moderno.

\footnotetext{
9 Violoncelle

Instrument qui a succédé à la Viole pour accompagner dans les Concerts. Il est fait comme le Violon, excepté qu'il est beaucoup plus gros, \& se tient entre les jambes.

Le P. Tardieu, de Tarascon, frère d'un célèbre Maître de Chapelle de Provence, l'imagina, vers le commencement de ce siècle ; il le monta de cinq cordes, ainsi accordées.

ut, sol, re, la, re:

Bourdon, deuxième, troisième, quatrième, chanterelle ;

II fit une prodigieuse fortune avec cet instrument, dont il jouait bien. Quinze ou vingt ans après, on réduisit Violoncelle à quatre cordes, en lui ôtant sa chanterelle re.
} 
O violoncello Piccolo a 4 e 5 cordas: uma análise através...

Edoardo Sbaffi

Figura. 1: LA BORDE, Jean Benjamin de. Essai sur la musique ancienne et moderne, Tome Premier, p. 309.

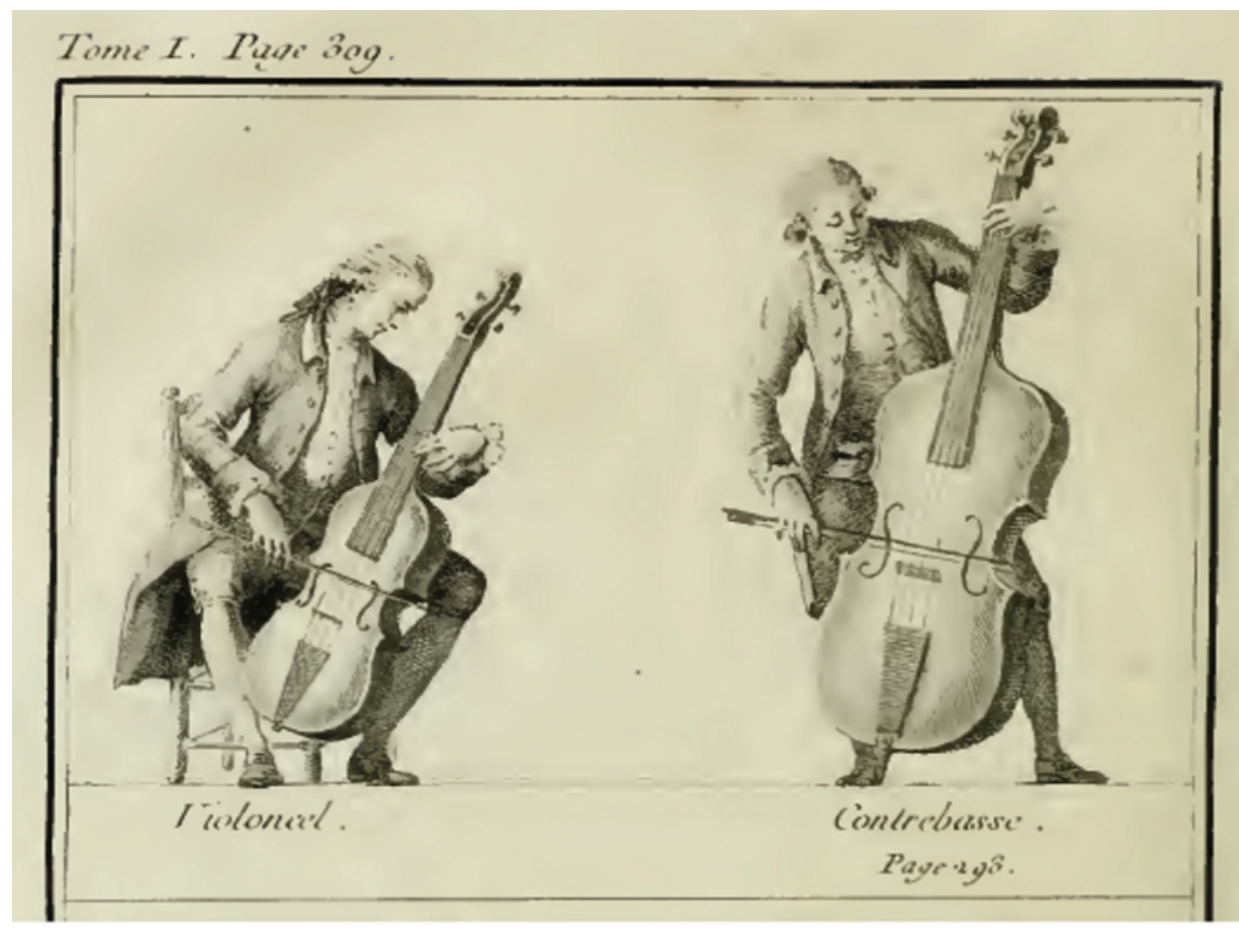

Os tratados musicais contam o saber dos músicos ao longo da história e através deles aprendemos muito do que sabemos sobre a arte musical do passado. Eles têm, porém, um limite: os seus autores falam aos seus contemporâneos, considerando muitos conceitos como óbvios e prescindindo frequentemente de explicações. A organologia histórica encontra assim, nessa tipologia de fontes, muitas limitações, particularmente quando os textos não são acompanhados por gravuras e desenhos.

Resumindo o que foi dito até aqui: tanto La Borde como Mozart consideram o violoncelo a 5 cordas um progenitor do violoncelo a 4 cordas. Os tratados citados, escritos ao longo do século XVIII, atestam que o uso do violoncelo a 5 cordas (em Brossard e Mozart) e do violoncelo Piccolo, tanto da Spalla como da Gamba (em Mattheson e La Borde), era comum pelo menos na França e na Alemanha. O fato de se utilizar o nome violoncello sem ulteriores adjetivos é ligado a um modelo de classificação organológica 
O violoncello Piccolo a 4 e 5 cordas: uma análise através...

pré-iluminista bem mais livre e menos acurado daquele a que estamos acostumados hoje em dia.

Os instrumentos originais conservados em museus e coleções particulares apresentam o problema de evidenciar constantes dúvidas de autenticidade. Era prática frequente intervir nos instrumentos para "modernizá-los", adaptando-os às novas exigências do mercado musical. Essas intervenções dos liuthiers do passado são difíceis de individuar e representam um sério obstáculo quando se trata de definir pormenores organológicos e elementos característicos das diferentes épocas partindo da observação direta dos instrumentos antigos. A cultura museológica de conservação dos instrumentos musicais é relativamente recente na nossa sociedade, tendo aparecido ao longo da segunda metade do século XIX. Até então um instrumento que deixasse de ser utilizado (as liras renascentistas, assim como os cravos e as violas da gamba no final do século XVIII) perdia qualquer valor comercial e acabava facilmente abandonado e destruído ou, quando possível reconvertido em algo que tivesse alguma utilidade. Os instrumentos antigos foram assim sucessivamente adaptados às novas exigências do mercado. A reconversão de instrumentos antigos, particularmente aqueles saídos de ateliês de famosos construtores, tornou-se um negócio notável no século XIX e tão atrativo que muitos liuthiers deixaram de fabricar novos instrumentos para dedicar-se exclusivamente a isso. Esta lucrativa atividade foi um dos fatores que contribuíram para o declínio da arte de construir instrumentos da família do violino na Europa, em geral, e na Itália, em particular, a partir do século XIX.

Perante uma terminologia frequentemente contraditória e imprecisa encontrada nas fontes primárias e constatando a dificuldade objetiva da observação direta dos instrumentos antigos, a análise iconográfica representa um válido campo de investigação científica na organologia histórica. Pinturas e esculturas podem se deteriorar ao longo dos séculos, mas são uma referência quase "certa" do que se fazia numa determinada área geográfica e num determinado período. É importante, porém, saber interpretar cor- 
O violoncello Piccolo a 4 e 5 cordas: uma análise através...

Edoardo Sbaffi

retamente esta preciosa fonte: alguns artistas estavam pouco interessados no realismo do instrumento representado e na postura do músico, de onde nós deduzimos respectivamente as características organológicas e as técnicas executivas. Esta última podia ser modificada por razões estéticas ou simplesmente por desinteresse do autor da imagem. Outro problema com o qual nos deparamos ainda com alguma frequência é que, às vezes, o número de cravelhas não corresponde ao número de cordas nas representações dos instrumentos de cordas. A técnica utilizada para a representação simplesmente poderá não ter permitido a execução da quantidade certa de linhas sutis e paralelas no espaço exíguo e o realismo não pôde assim ser mantido.

Segue uma coletânea de iconografias organizada por ordem cronológica:

Figura. 2: Il Concerto, Escola fiorentina 1550-1600, Louvre musée, Paris.

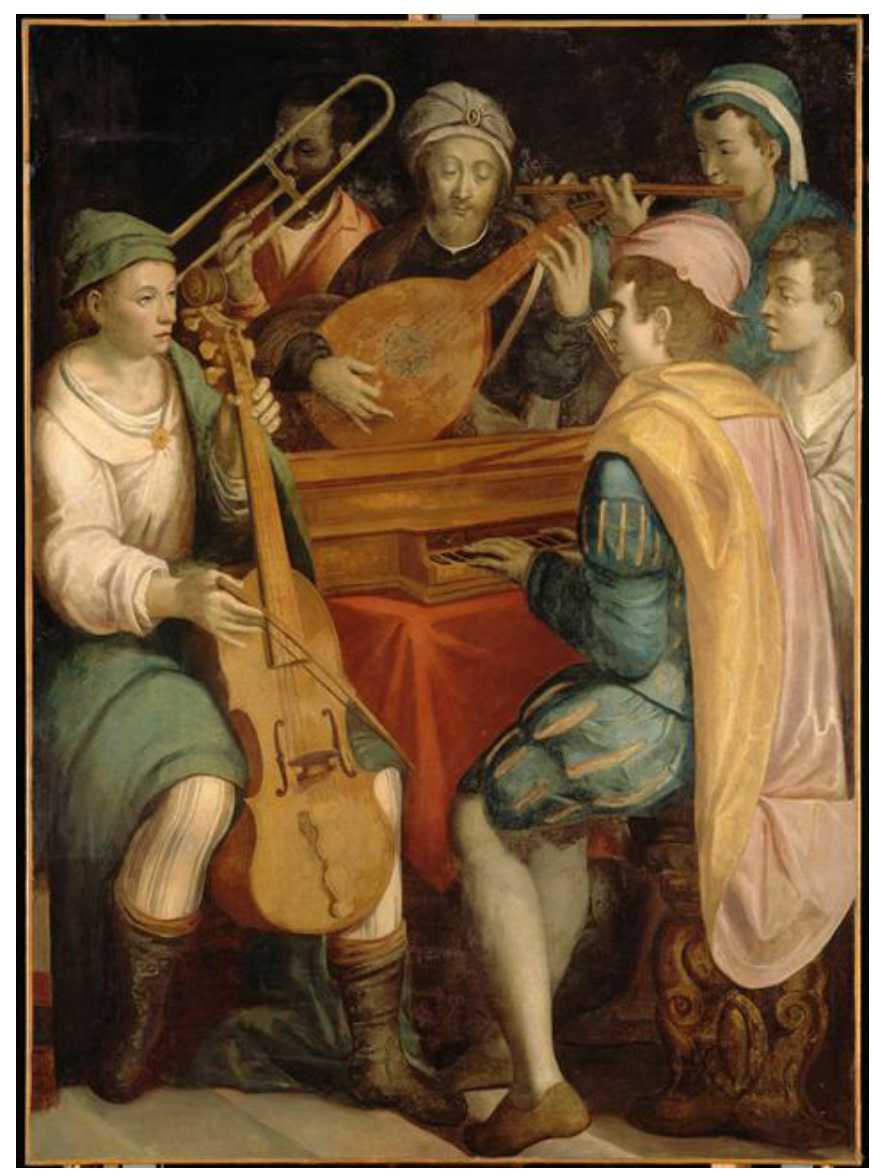


O violoncello Piccolo a 4 e 5 cordas: uma análise através...

Edoardo Sbaffi

O instrumento tocado pelo primeiro músico da esquerda será provavelmente uma viola da Gamba a 5 cordas pela presença de fretes e pelo fato de o tampo harmônico parecer ser plano: a morfologia das violas da Braccio e da Gamba na Itália do final de século XVI são muito parecidas ao ponto de a distinção entre as duas famílias começar a não fazer muito sentido ao longo do século XVII. Diferente é a situação nos outros países d'Europa, onde a Viola da Gamba ganha um espaço bem definido e um repertório próprio. A mesma dúvida surge observando a próxima imagem: o instrumento tanto pode ser um baixo de viola da Gamba como da Braccio.

Figura. 3: Annunciazione, fresco de Taddeo Zuccari, 1560 ca. Detalhe.

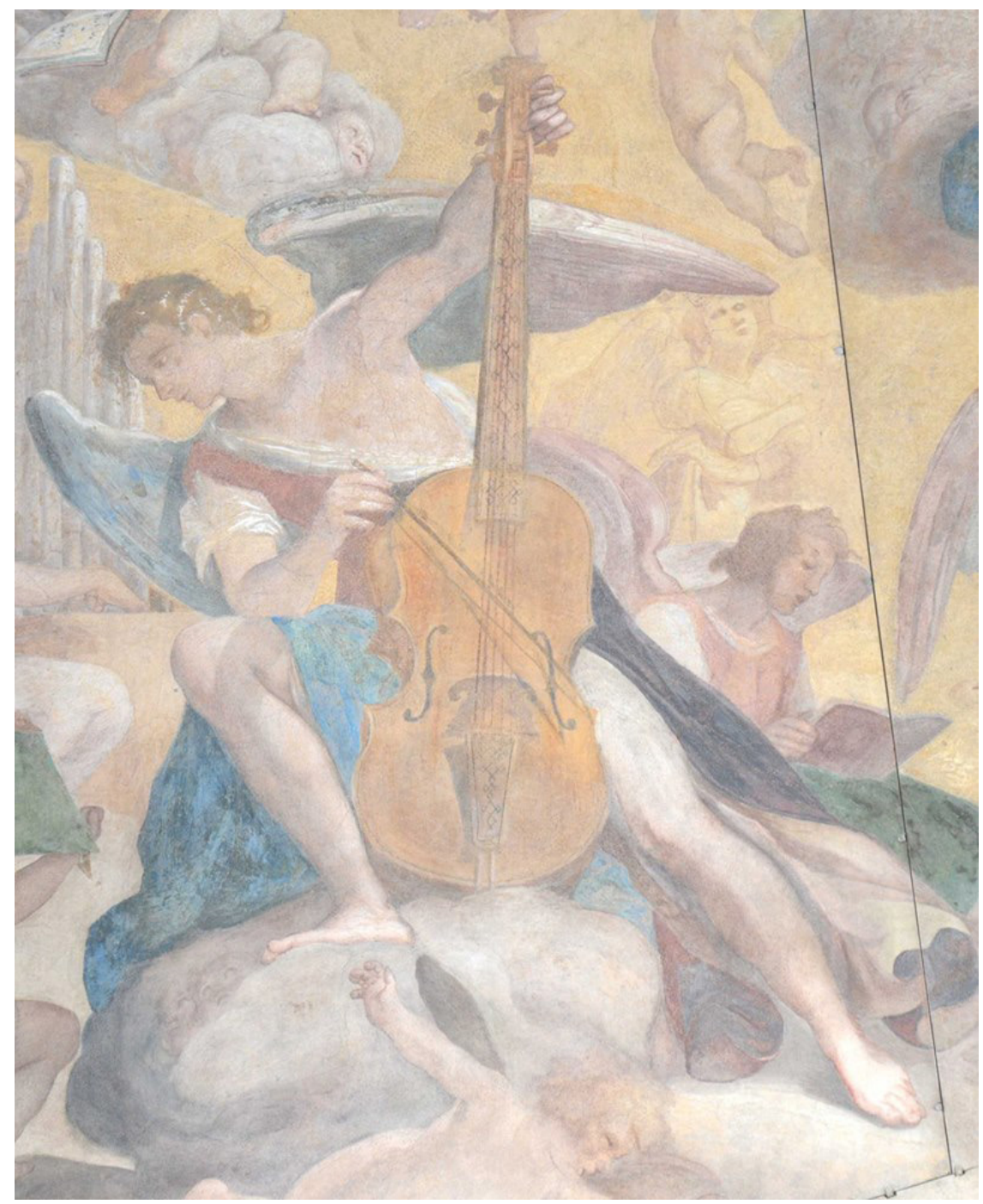


O violoncello Piccolo a 4 e 5 cordas: uma análise através...

Edoardo Sbaffi

Figura. 4: Anjo em madeira que integra um altar esculpido por Peter Spring (c.1593-1613), igreja de Saint-Maurice, Friburgo, Suíça.

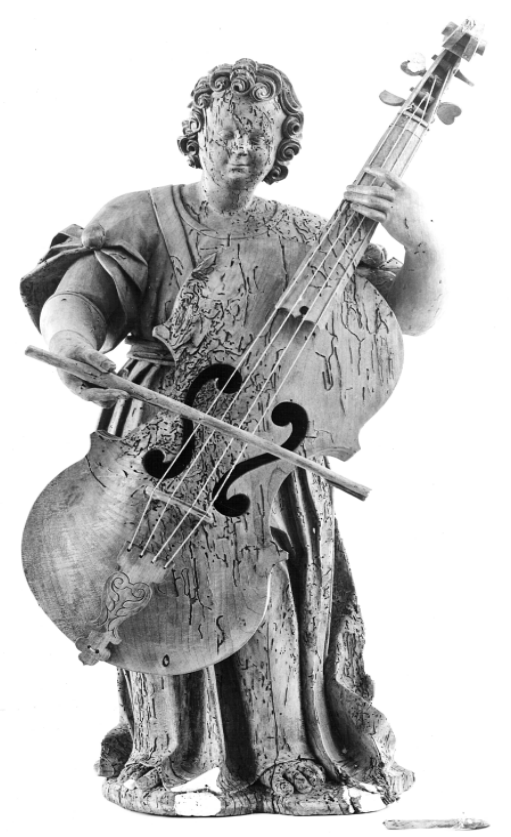

Nesta bonita escultura o violoncelo é sustentado quase verticalmente através de um gancho amarrado ao fundo do instrumento onde era realizado um orifício (ainda visível em vários instrumentos da época). Philibert Jambe de Fer descreve essa técnica no Epitome musical de 1556:
O italiano o chama violon (violino) da braccia (de braço) ou violone, porque sustenta-se nos braços, uns com uma echarpe, cordões, ou outra coisa, o Baixo por causa do seu peso é fortemente incómodo de transportar, portanto é sustentado com um pequeno gancho dentro de um anel de ferro, ou outra coisa, a qual é atacada exatamente nas costas do instrumento: de modo que não impeça quem tocar ${ }^{10}$. (JAMBE de FER, 1556, p. 63).

\footnotetext{
10 L'italien l'appelle Violon da Braccia ou violone, par ce qu'il se soustient sus les bras, les uns avec escharpe, cordons, ou autre chose, le Bas à cause de sa pesanteur est fort malayse à porter, pour autant il est sostenu avec un petit crochet das un anel de fer, ou d'autre chose, lequel est attaché au doz dudict instrument bien proprement: à celle fin qu'il n'empesche celuy quien ioue.
} 
O violoncello Piccolo a 4 e 5 cordas: uma análise através...

Edoardo Sbaffi

Figura. 5: Cena de teatro de rua, gravura na capa do Inventaire universel des oeuvres de Tabarin, Paris, 1622.

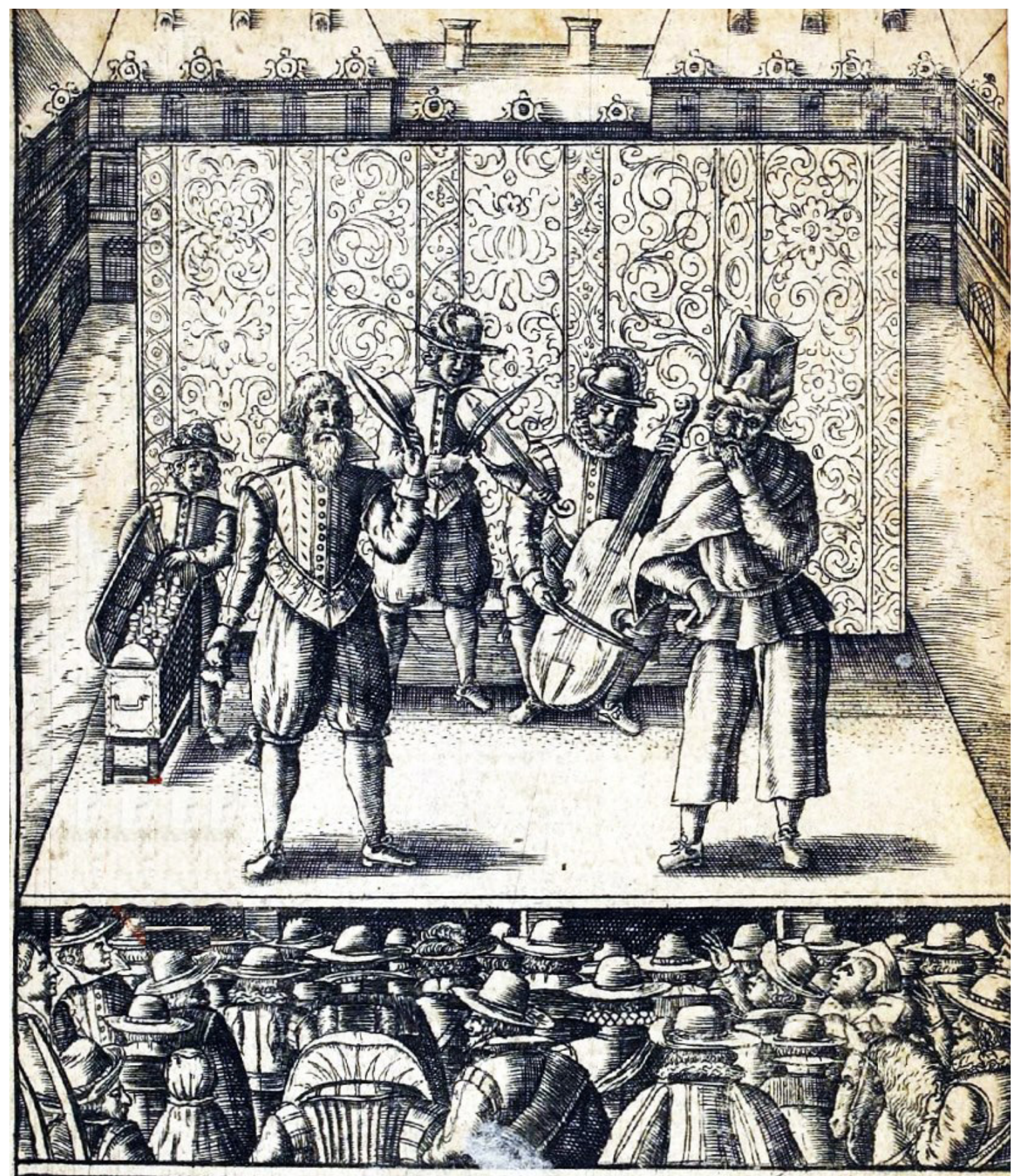

No Baixo que acompanha o violino juntamente a um órgão portativo, as cravelhas não são desenhadas, mas as 5 cordas são claramente visíveis. 
O violoncello Piccolo a 4 e 5 cordas: uma análise através...

Edoardo Sbaffi

Figura. 6: MANETTI, R. Messa di San Cerbone (detalhe), igreja de S. Maria in Provenzano, Siena, 1630.

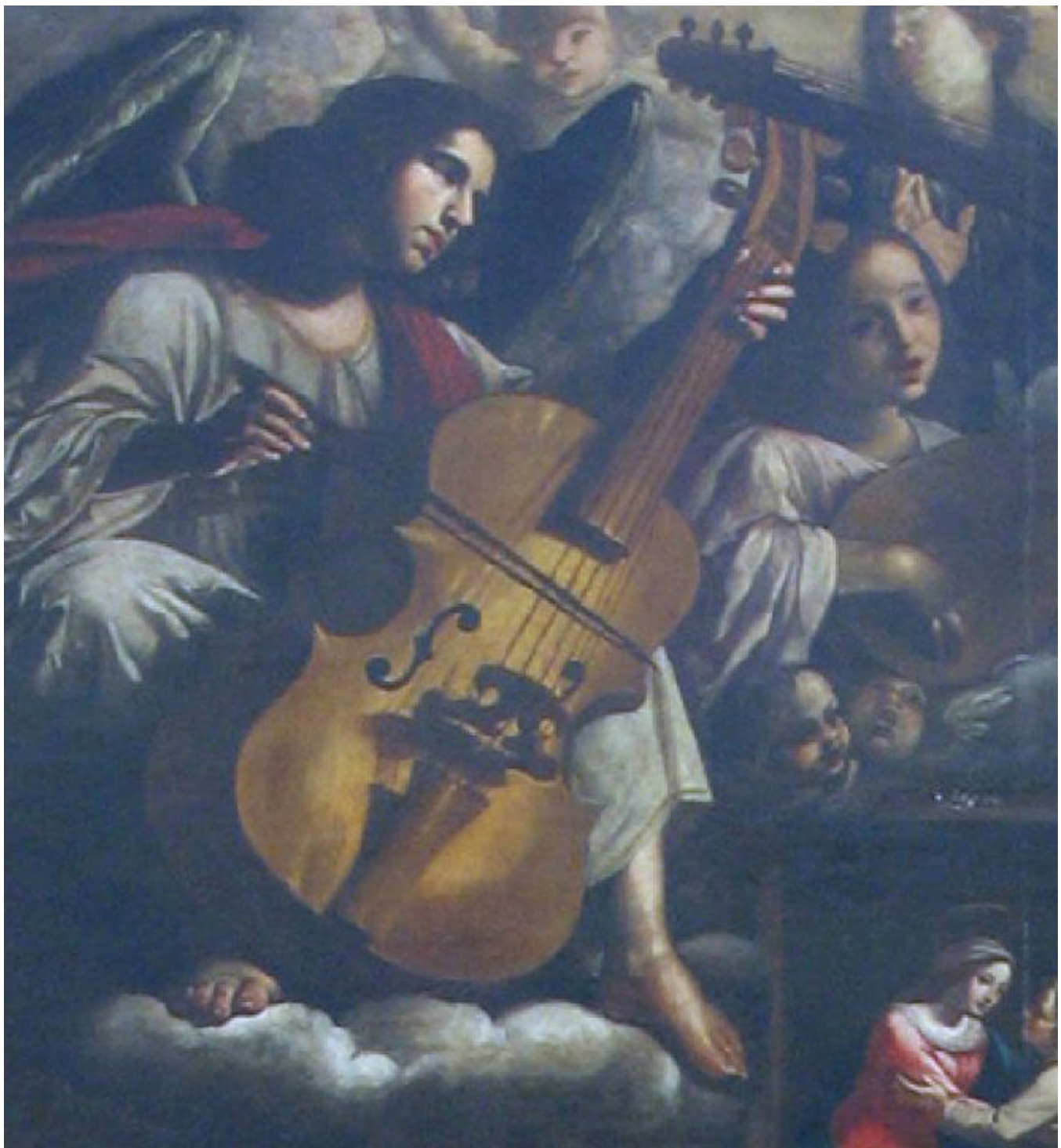

Nesta pintura há uma clara incongruência entre o número de cordas (aparentemente 4) e o número de cravelhas (6) desenhadas. Nas próximas três imagens, três pintores holandeses nos mostram, num curto espaço de tempo, violoncelos a 5 cordas de pequeno tamanho: 
O violoncello Piccolo a 4 e 5 cordas: uma análise através...

Edoardo Sbaffi

Figura. 7: CLAESZ, Pieter (1623). Musée du Louvre, Paris. Violone a 5 cordas.

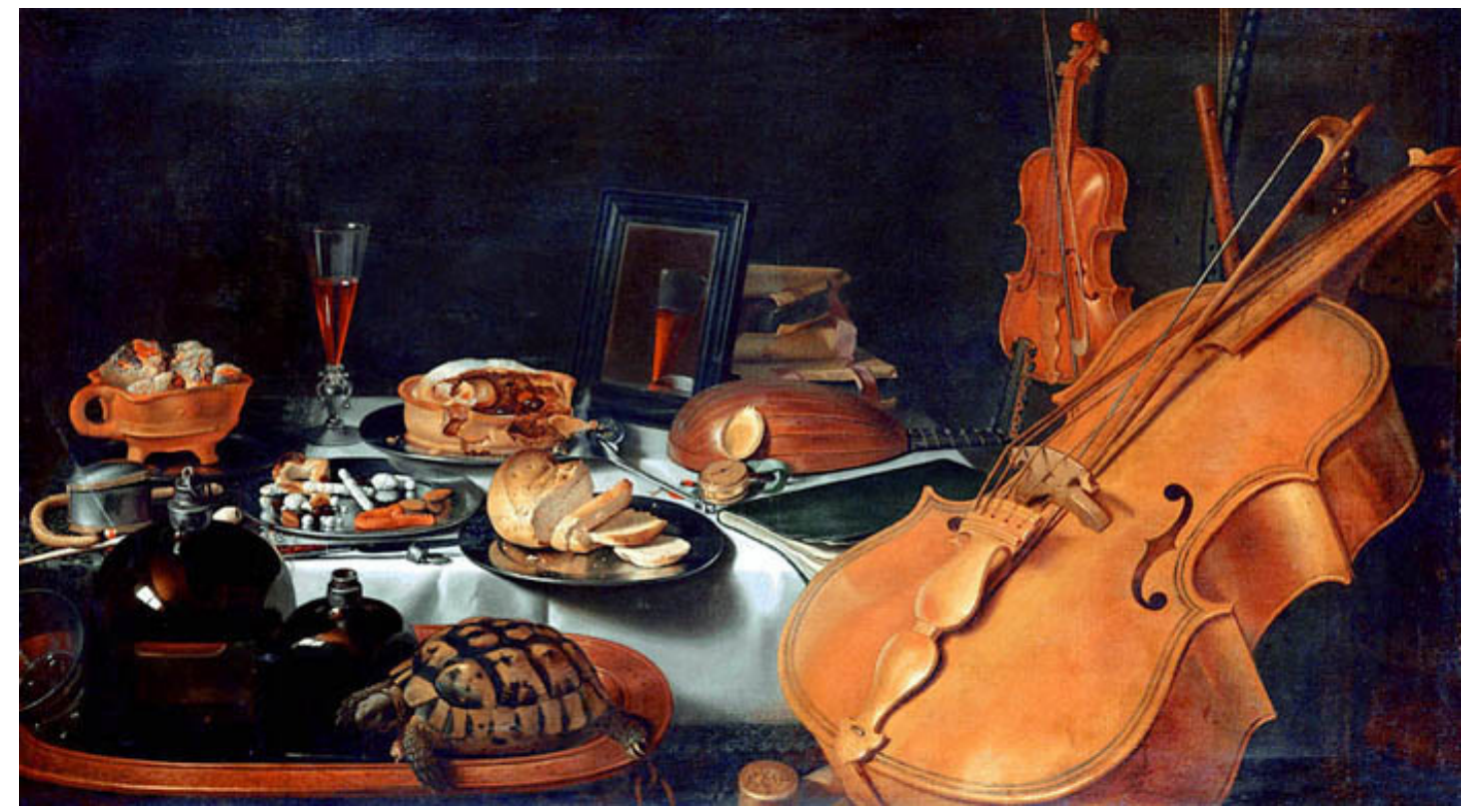

Figura. 8: VAN HONTHORST, Gerrit. The Concert, 1625, Roma, Galleria Borghese (detalhe).

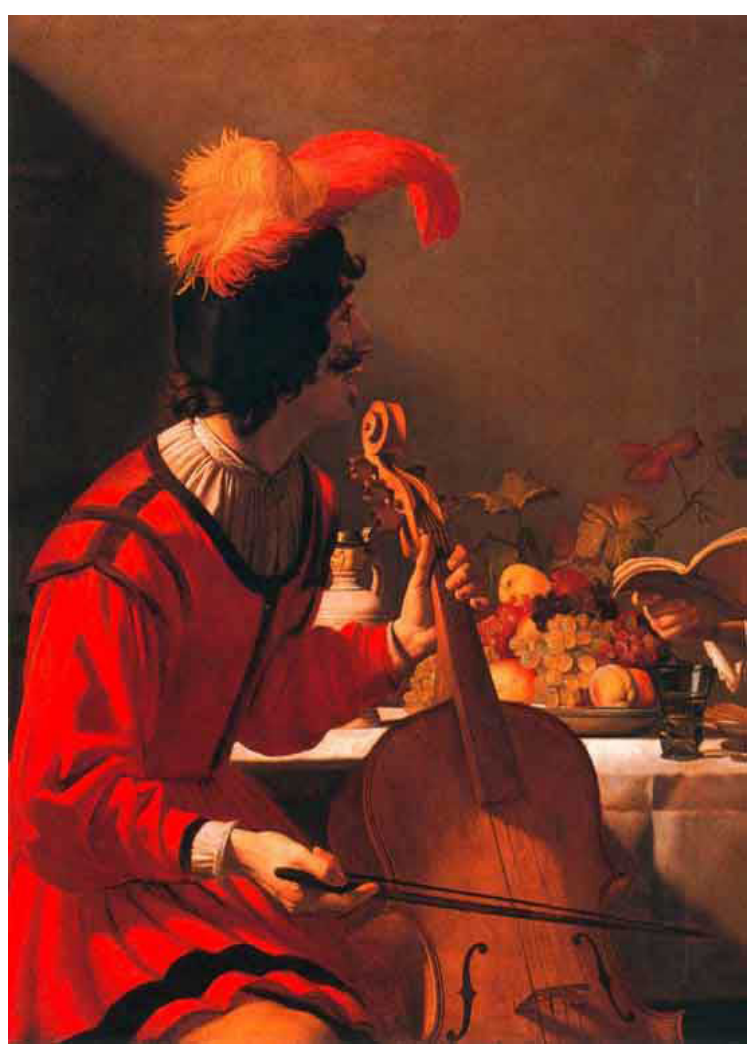


O violoncello Piccolo a 4 e 5 cordas: uma análise através...

Edoardo Sbaffi

Figura. 9: GERRITSZ, Jacob (1594 - c.1652). A Vanitas Still Life with an Angel Blowing Bubbles, Coleção privada.

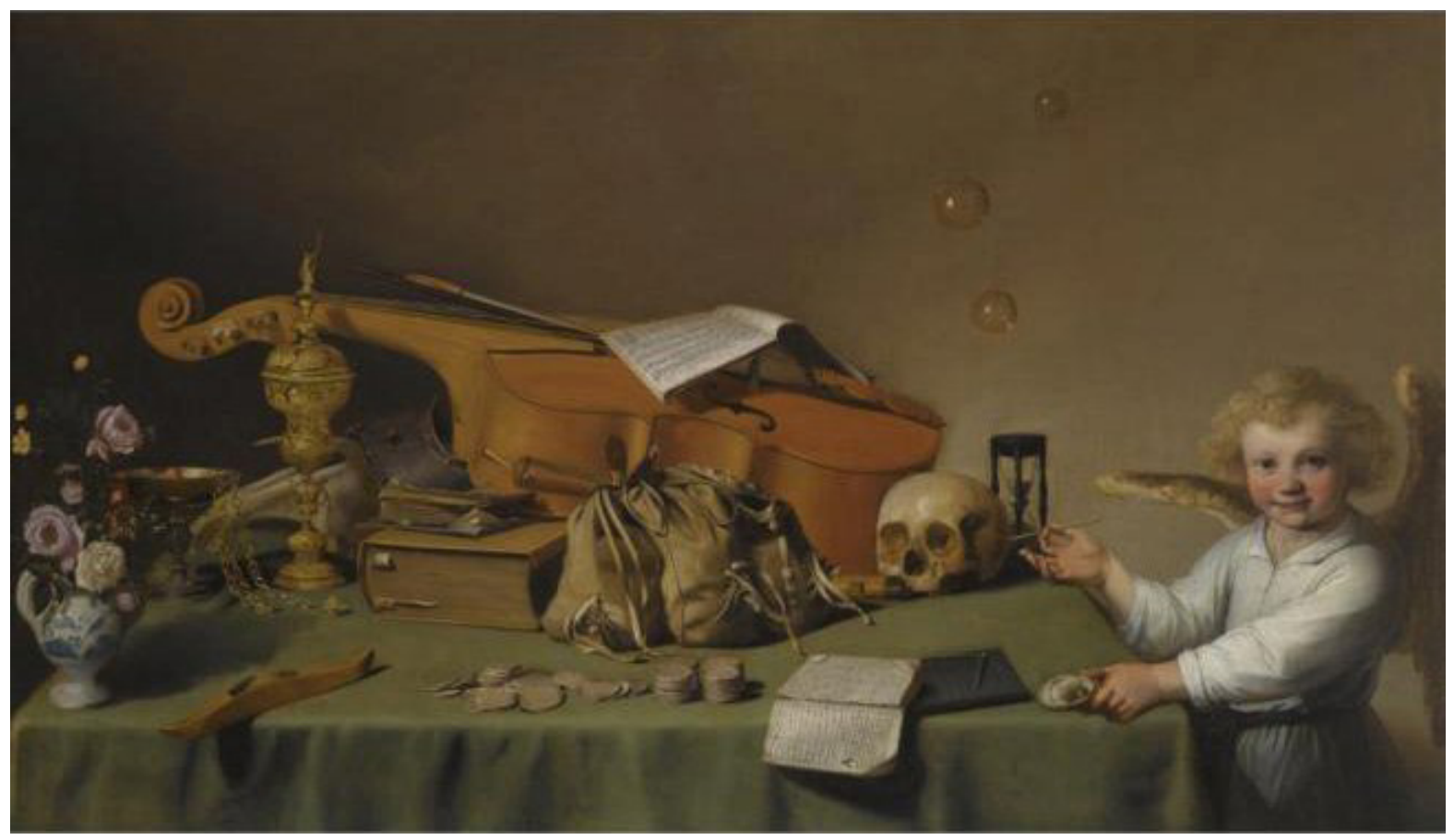

Constam acima mais três pinturas da escola Holandesa, representando agora violoncelos a 5 cordas claramente de tamanho maior e possivelmente ainda maior do que o violoncelo atual. É provável que sejam o violoncelo descrito por Brossad/La Borde com a quinta corda afinada em Ré (Bás de violon). 
O violoncello Piccolo a 4 e 5 cordas: uma análise através...

Edoardo Sbaffi

Figura. 10: PALAMEDESZ, Antonie. Party Scene with Music, 1635-40.

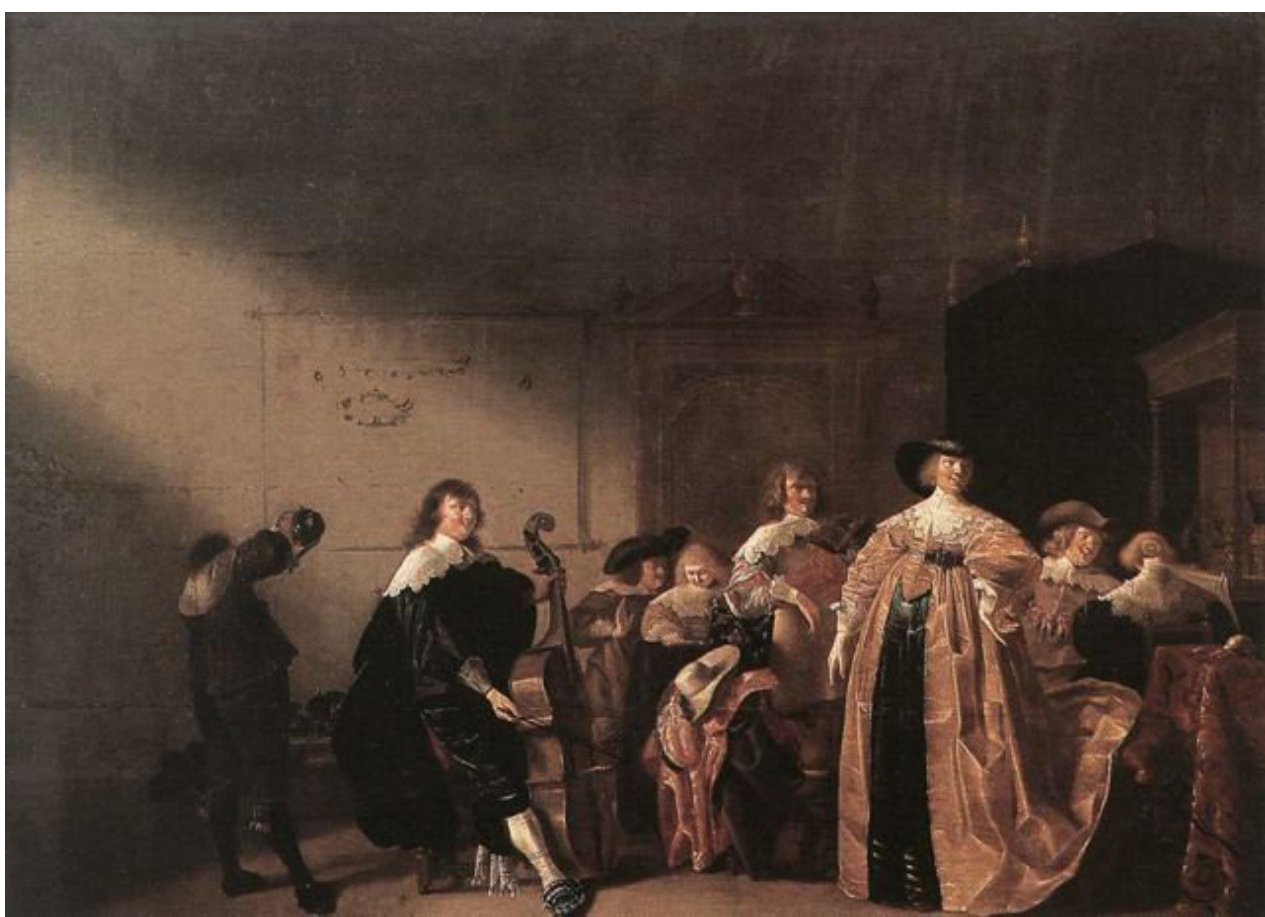

Figura. 11: METSU, Gabriel. Woman at Her Toilette, c.1658, The Norton Simon Foundation, Pasadena (detalhe).

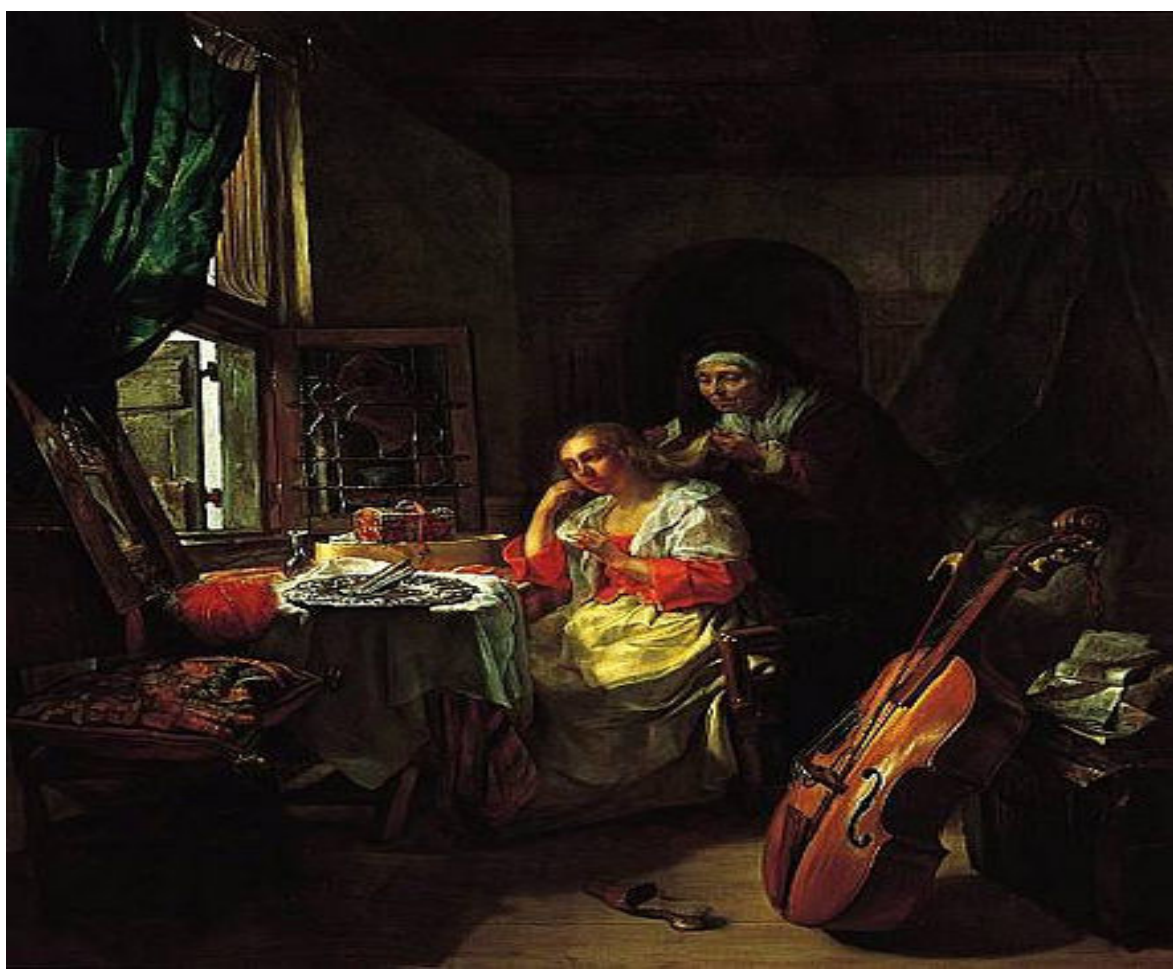


O violoncello Piccolo a 4 e 5 cordas: uma análise através...

Edoardo Sbaffi

Figura. 12: MOLENAER, Jan Miense (1610-1668). Merry Company on terrace Sun.

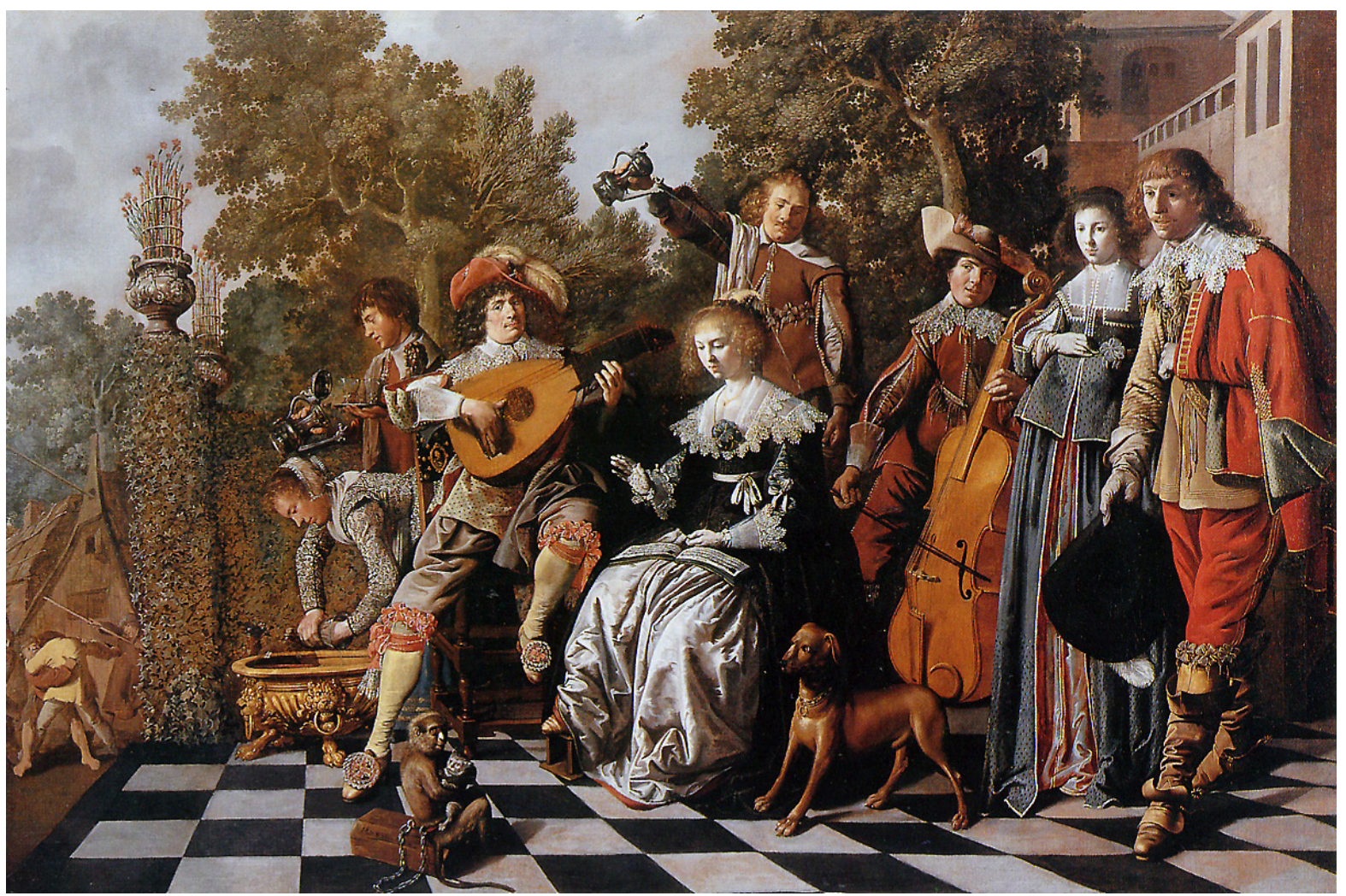

A pintura do francês François Puget (abaixo) finaliza o século XVII com mais um violoncelo a 5 cordas de tamanho bastante grande, instrumento bem parecido com os instrumentos das últimas três figuras. 
O violoncello Piccolo a 4 e 5 cordas: uma análise através...

Edoardo Sbaffi

Figura. 13: PUGET, François. Réunion de musiciens, 1688, Musée du Louvre, Paris.

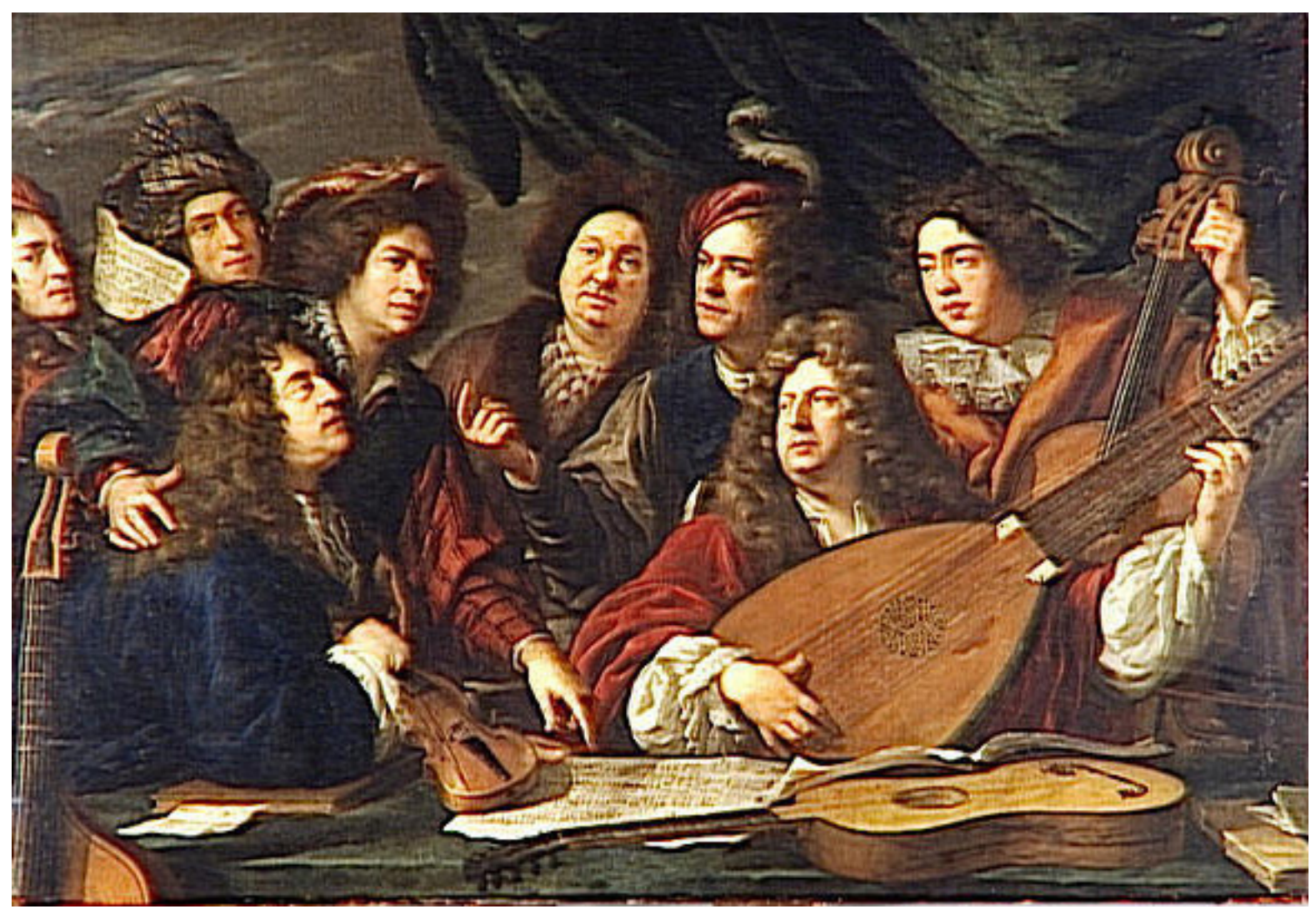

Em seguida, há duas gravuras do século XVIII ilustrando dois grandes violoncelistas italianos da época e seus instrumentos a 5 cordas: 
O violoncello Piccolo a 4 e 5 cordas: uma análise através...

Edoardo Sbaffi

Figura. 14: O célebre violoncelista Giacobbe Basevi dito "il Cervetto" (1682 1783) numa gravura inglesa da época.

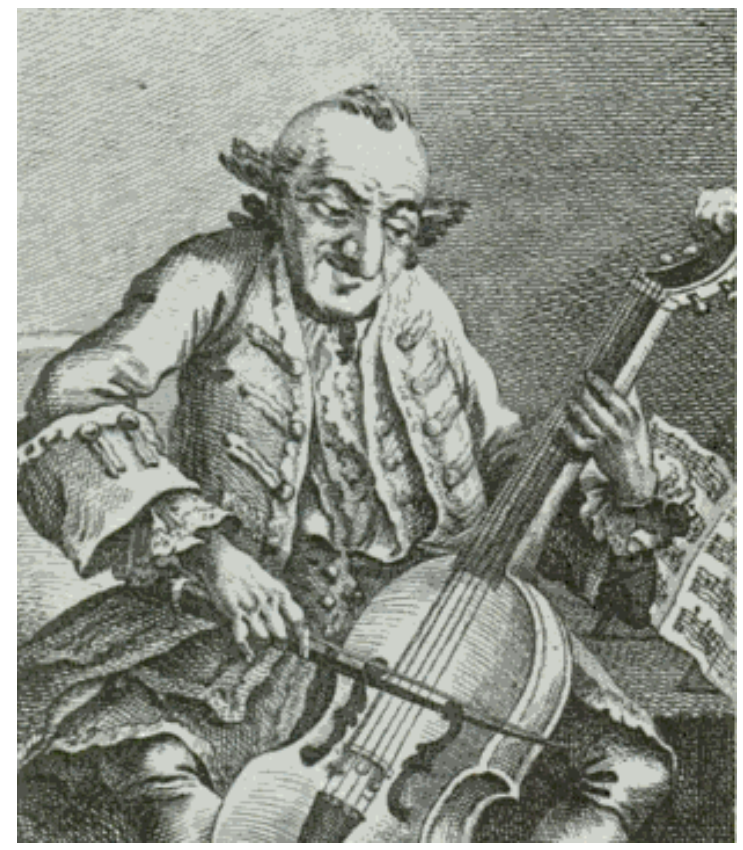

Figura.15: O violoncelista Andrea Caporale numa gravura inglesa (c.1740). Detalhe. Disponível em: http://commons.wikimedia.org/wiki/File:Handel_regendo.jpg

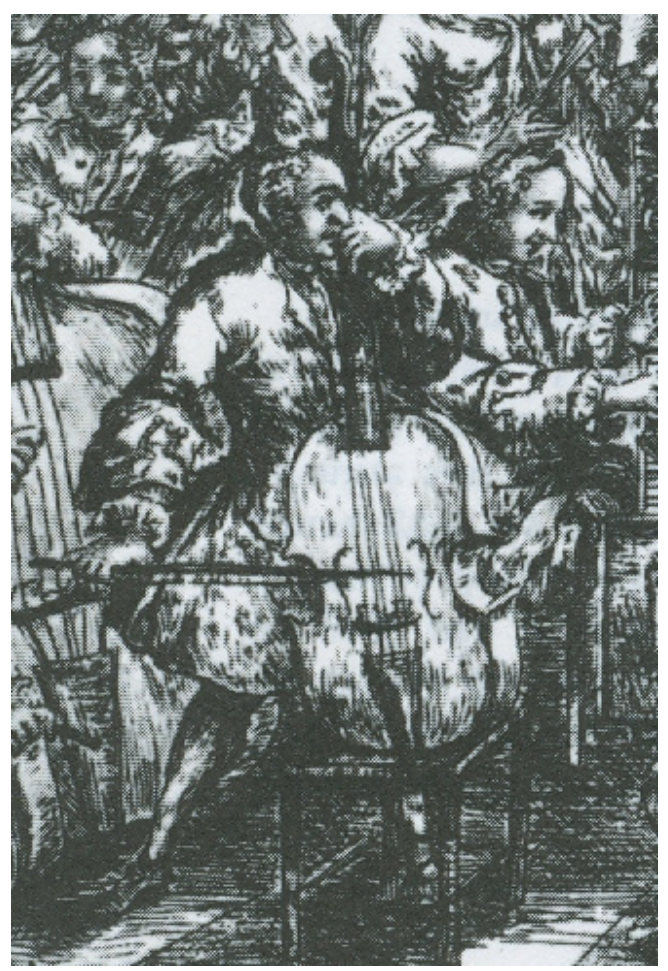


O violoncello Piccolo a 4 e 5 cordas: uma análise através...

Edoardo Sbaffi

Os instrumentos representados nas Figuras 7 e 8 (dos holandeses Van Honthorst e Jacob Gerritsz) são de tamanho menor do que um violoncelo moderno: as 5 cordas em tripa não revestida levantam um problema de afinação. As pinturas são de época anterior à invenção das cordas revestidas, delas temos a primeira referência só em 1659 e sua difusão acontece somente na década sucessiva (PERUFFO, 1997). A corda mais grave, se afinada em Dó (a quarta corda do violoncelo moderno) teria, com esse comprimento, um resultado acústico péssimo. É mais razoável pensar numa afinação em Fá ou Sol na corda grave; assim o limite agudo do instrumento seria em torno do Ré ou Mi acima do Dó central. A afinação por intervalo de quintas, que caracteriza a família das violas da Braccio, é, portanto, improvável nesses instrumentos. Encontramos o mesmo dilema no violoncelo a 5 cordas dos irmãos Antonio e Hieronimus Amati, construído na primeira década de 1600, cujo comprimento de corda vibrante é de $64,2 \mathrm{~cm}$ (contra os 69 do violoncelo moderno).

Figura.16: Violoncelo dos irmãos A \& H Amati, Cremona, c.1610, atualmente pertencente à Amaryllis Fleming Foundation.

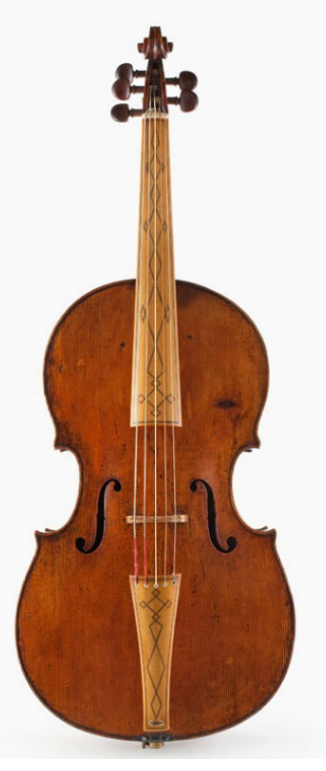

Finalizamos a resenha iconográfica com duas últimas imagens que retratam violoncelos pequenos a 4 cordas: o primeiro tocado 
O violoncello Piccolo a 4 e 5 cordas: uma análise através...

Edoardo Sbaffi

em posição vertical e apoiado num banquinho (em posição, portanto, não da gamba) com o arco em posição prona. No segundo podemos somente fazer a comparação da proporção do instrumento com o músico amador: constata-se assim que o violoncelo é claramente menor do que seria espectável por um adulto.

Figura. 17: 0 texto de baixo da gravura é do Dmitry Badiarov (2007: 134).

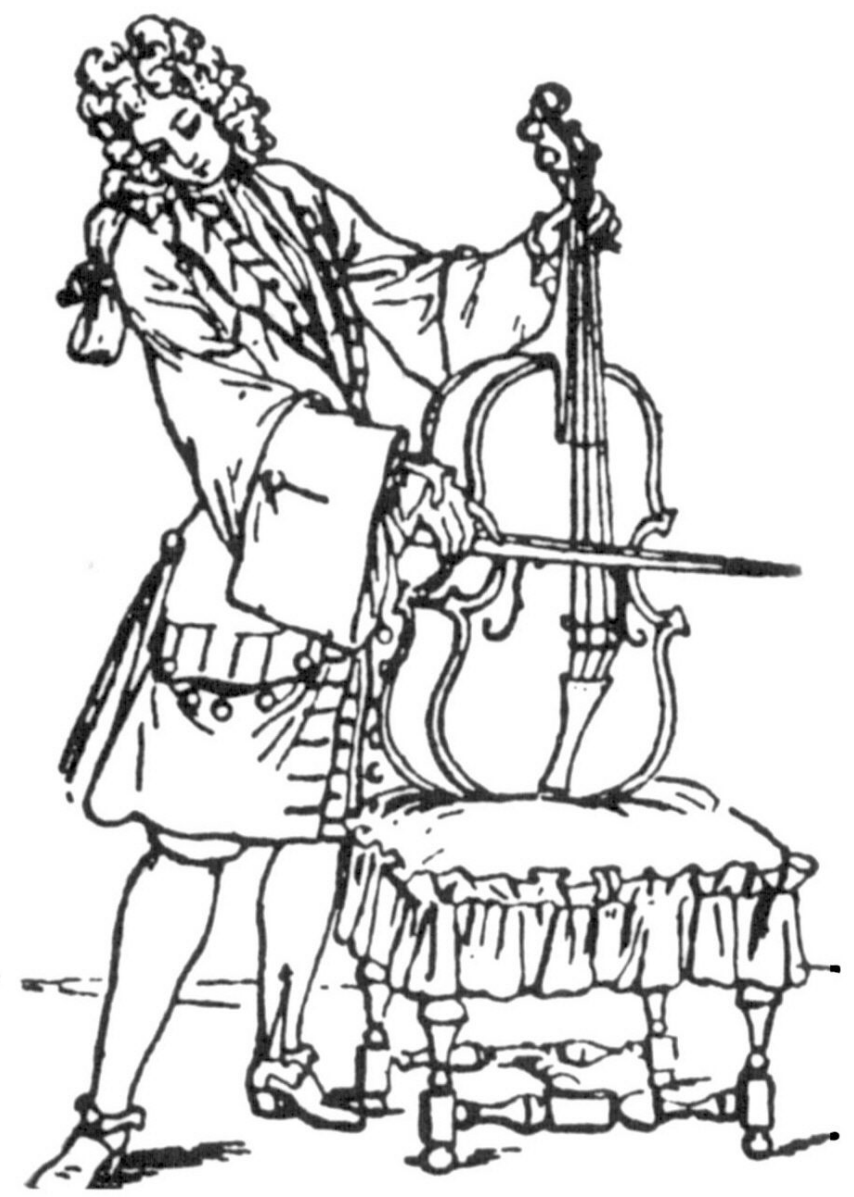

Figure 1. Bernard Picart, Print of a Musician, 1701 (detail). The instrument in this picture is clearly smaller than a full size modern cello, and as Drüner explains, the picture means that such instruments cannot properly be designated 'children's cellos'. The full print is illustrated in Maurice Riley, The History of the Viola, vol.1, (Ann Arbour, 1993), p.96. 
O violoncello Piccolo a 4 e 5 cordas: uma análise através...

Edoardo Sbaffi

Figura. 18: Cornelis Troost (1697 - 1750), Portrait of a music lover of the Van der Mersch family, 1736, detalhe (Amsterdam, Rijksmuseum).

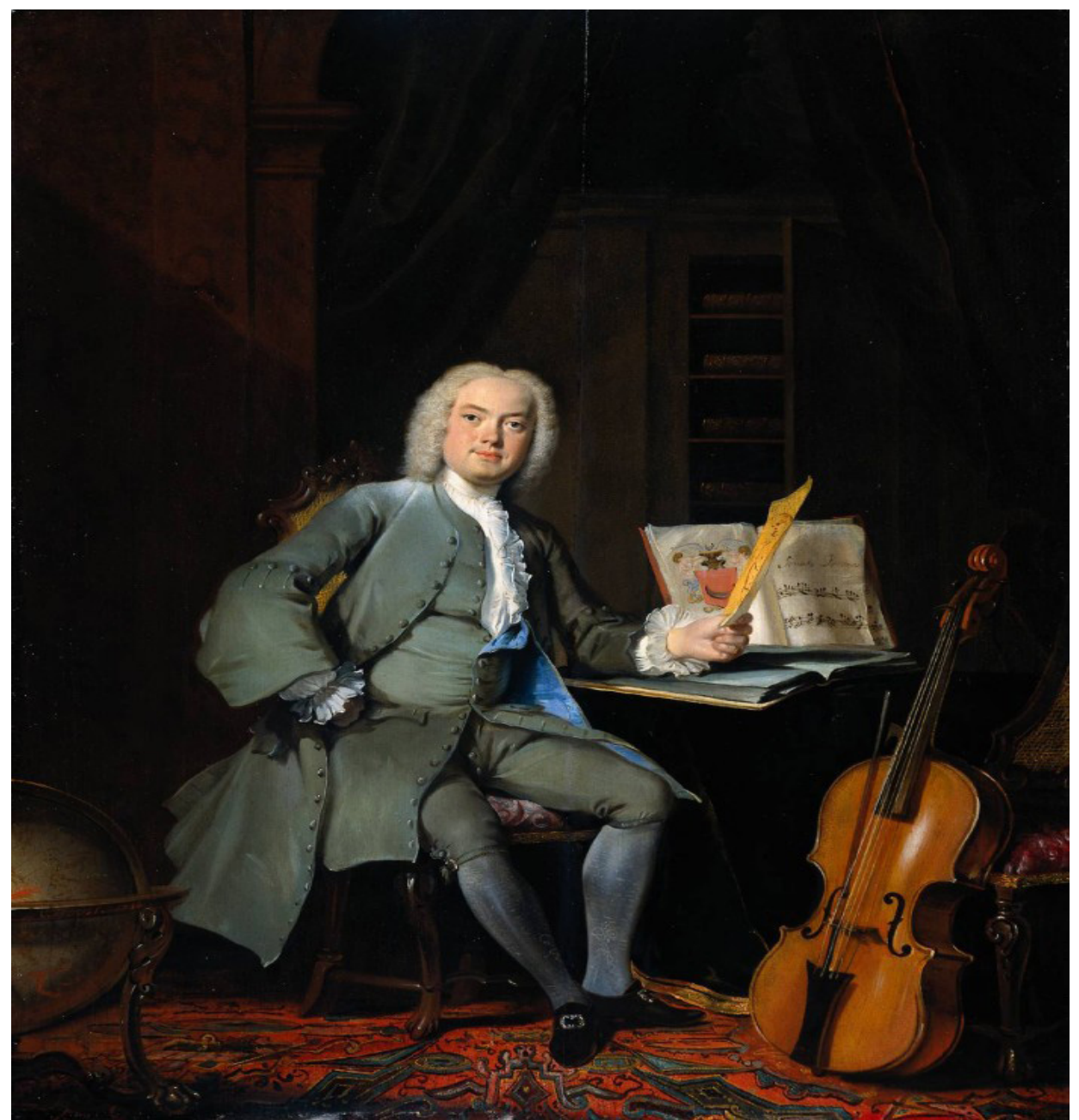

Nesses violoncelos de pequeno tamanho, a corda grave não teria condições de produzir um som de qualidade no registro de 8 pés (o Dó grave do violoncelo); a hipótese mais provável é uma afinação Sol-Ré-Lá-Mi (uma oitava abaixo do violino). A confirmação da existência dessa afinação é encontrada no "Musurgiae universalis", de 1650, do erudito jesuíta Athanasius Kircher, onde o "violone" (que o Athanasius chama, em latim, de Chelys maioris, o termo violoncelo seria inventado poucos anos depois) é comparado com a viola da Gamba (Chelys hexachorda), sendo explicitada a afinação dos dois instrumentos de forma inequívoca. 
O violoncello Piccolo a 4 e 5 cordas: uma análise através...

Edoardo Sbaffi

Figura. 19: KIRCHER, Athanasius. Musurgiae universalis, Roma, 1650, p. 487. (Detalhe).

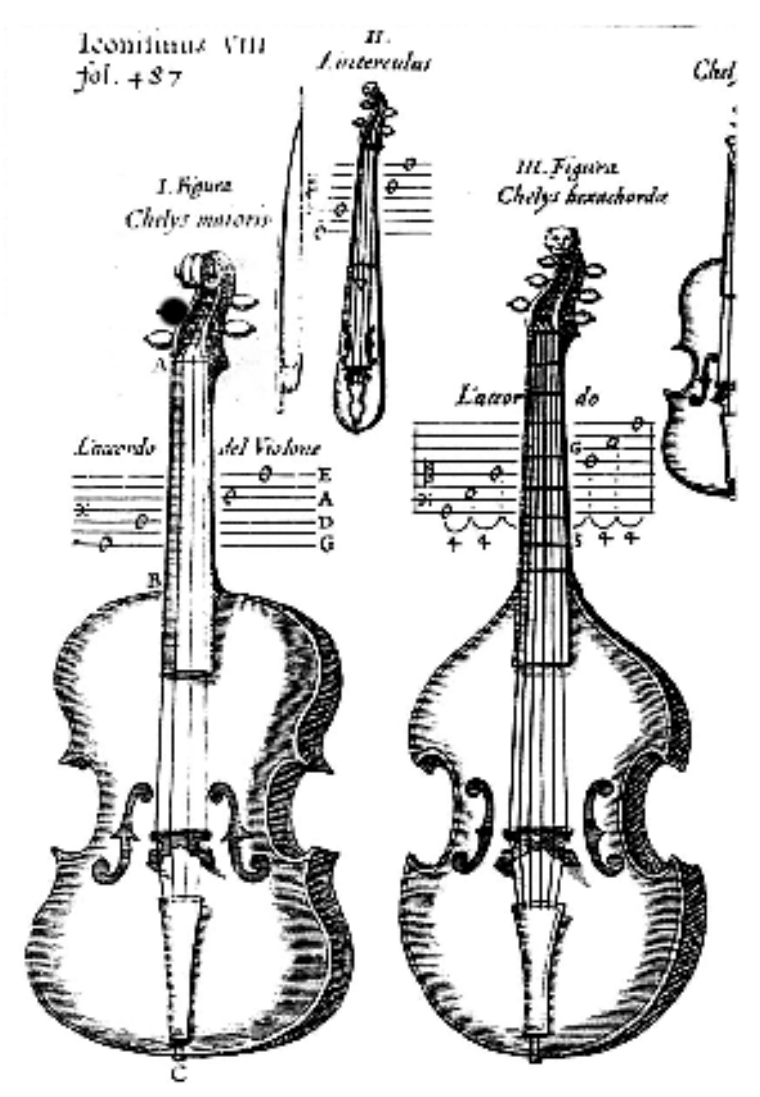

\section{Conclusões}

Este trabalho visa a redefinir e ampliar o termo organológico de violoncelo barroco incluindo os modelos a 4 e 5 cordas de pequeno tamanho (violoncelo piccolo) e os violoncelos de tamanho normal ou até maior do que o modelo atual, mas com 5 cordas. Ao mesmo tempo constatam-se várias técnicas de execução frequentemente desconhecidas ou ignoradas por muitos violoncelistas de hoje, mesmo entre os que se definem como "historicamente informados"; são eles variantes da técnica da Gamba (apoiado o ins- 
O violoncello Piccolo a 4 e 5 cordas: uma análise através...

Edoardo Sbaffi

trumento num banquinho ou no chão) e da Spalla/da Collo onde o instrumento, normalmente, mas não necessariamente menor, era sustentado horizontalmente no ombro ou no peito com o auxílio de um cinto. Demonstra-se, através de pesquisa em tratados musicais tanto do século XVII (Bismantova, Kircher) como do século XVIII (Brossard, Mattheson, Mozart e La Borde), que o violoncelo a 5 cordas é, de fato, um progenitor do violoncelo a 4 cordas e foi utilizado até a primeira metade do século XVIII e que o uso do violoncelo a 5 cordas e do violoncelo piccolo, tanto da Spalla como da Gamba, era comum pelo menos na França, nos Países Baixos e em parte da Alemanha. As nossas teses ganham um importante apoio na pesquisa iconográfica em que os modelos e as técnicas são expostos sem a ambiguidade dos textos antigos, nos quais a terminologia é, às vezes, confusa e inexata.

\section{Referências}

Arresti, Giulio Cesare. Sonate a 2 e a Tre con la parte del violoncello A beneplacito Op.IV. Venezia: Magni, 1665.

Bismantova, Bartolomeo.Compendio Musicale. Ferrara: documento MANUSCRITO, 1677. DisPonívEL EM: HTTP://PETRUCCI.MUS.AUTH.GR/IMGLNKS/ USIMG/5/59/IMSLP500785-PMLP510627-BISMANTOVA_\%E2\%80\%94_ COMPENDIO_MUSICALE_1677.PDF

BOnTA, Stephen. From Violone to Violoncello: A Question of Strings?. JAMIS III, 1977, p. 77-78.

BadiaroV, Dmitry. The Violoncello, Viola da Spalla and Viola Pomposa in Theory and Practice. Galpin Society Journal, apr. 2007, P. 121-145. jambe DE fer, Philibert. Epitome musical des tons, sons et accordz, et voix humaines. Lyon: Michel du BoIs, 1556. 
O violoncello Piccolo a 4 e 5 cordas: uma análise através...

Edoardo Sbaffi

LA BORDE, Jean Benjamin de. Essai sur la musique ancienne et moderne, Tome Premier. Paris: Eugene Onfroy, 1780.

BROSSARD, Sébastien De. Dictionaire de musique, contenant une eXplicaTION DES TERMES GRECS, LATINS, ITALIENS \& FRANÇOIS, LES PLUS USITEZ DANS LA musique. 2 ed. Paris: C. Ballard, 1703.

KirCher, Athanasius. Musurgiae universalis. Roma: Haeredum F. Corbelletti,1650.

MatTheson, Johann. DasNeu-eröffnete Orchestre. Hamburg: B. SchilLER, 1713.

MOZART, Leopold. Versuch einer gründlichen Violinschule. Augsburg: JOHANN JACOB LOTTER, 1756.

PERUFFO, Mimmo. ItALIAN VIOLIN STRINGS IN THE EIGHTEENTH AND NINETEENTH CENTURIES: TYPOLOGIES, MANUFACTURING TECHNIQUES AND PRINCIPALS OF STRINGING. Updated VERSiOn OF the ORIGINAL ARTICLE In ReCERCARe IX, 1997, p. 155-203. SACHS, Curt. The History of Musical Instruments. W. Norton \& ComPANY, NEW YORK, 1940, 505P. 